\title{
A COMPARATIVE STUDY OF INTRATHECAL BUPIVACAINE WITH FENTANYL AND BUPIVACAINE WITH MIDAZOLAM IN LOWER ABDOMINAL AND LOWER LIMB SURGERIES
}

\author{
Holalu Shankaregowda Suraj ${ }^{1}$, Vinod C. $N^{2}$
}

${ }^{1}$ Assistant Professor, Department of Anaesthesiology, Kempegowda Institute of Medical Sciences and Research Centre, Bangalore. ${ }^{2}$ Assistant Professor, Department of Anaesthesiology, Kempegowda Institute of Medical Sciences and Research Centre, Bangalore.

\section{ABSTRACT}

\section{BACKGROUND}

Various adjuvants are being used with local anaesthetics in spinal anaesthesia for prolongation of intraoperative and postoperative analgesia. Fentanyl is a lipophilic $\mu$ receptor agonist opioid, neuraxial adjuvant compared with Midazolam, Benzodiazepine used as Neuraxial adjuvant with Bupivacaine.

Aim- To compare and evaluate the onset and duration of sensory and motor blockade, Haemodynamic effect, post-operative Analgesia and adverse effects of fentanyl and Midazolam given intrathecally with hyperbaric $0.5 \%$ bupivacaine.

\section{MATERIALS AND METHODS}

100 patients belonging to ASA Grade-I and Grade-II of both sexes (each group 50 patients, $\mathrm{n}=50$ ) were selected for the study. Group-F received $3 \mathrm{~mL}$ of $0.5 \%$ Hyperbaric Bupivacaine with $0.5 \mathrm{~mL}$ ( 25 micrograms) of Fentanyl. Group-M received $3 \mathrm{~mL}$ of $0.5 \%$ hyperbaric Bupivacaine with $0.5 \mathrm{~mL}(25 \mathrm{mg}$ ) of Midazolam. The time onset of sensory and motor block, Haemodynamic status, time for two dermatomal segments regression of sensory level to L2 dermatome, time of first request of analgesics, visual analgesic score and adverse effect were compared in both the groups. Data obtained were tabulated and analysed using statistical package for social science (SPSS 16.0 evaluation version). Descriptive data are presented as mean \pm SD. The difference between variables were calculated by student's ' $t$ ' test and chi square test at $5 \%$ level of significance.

\section{RESULTS}

Patients in Fentanyl group (Group F) had a significantly longer sensory and motor block than patients in Midazolam group (Group $\mathrm{M})$. The mean time of sensory regression to $\mathrm{L} 2$ was $(172.30 \pm 5.08 \mathrm{~min})$ in Group F and (147.30 $\pm 8.71 \mathrm{~min})$ in Group M. The regression time of motor block to reach Bromage 0 was (201.20 $\pm 29.63 \mathrm{~min})$ in Group F and (183.20 $\pm 5.88 \mathrm{~min})$ in Group M. The time to rescue analgesia was significantly longer in Group F (381.67 $\pm 38.9 \mathrm{~min})$ as compared to Group M (226.67 $\pm 15.2 \mathrm{~min})$.

\section{CONCLUSION}

Intrathecal administration of 25 microgram of fentanyl in combination with hyperbaric Bupivacaine $0.5 \%$ produces better quality of Analgesia, longer duration of Analgesia with mild sedation and minimal side effects compared to Intrathecal administration of $2.5 \mathrm{mg}$ of Midazolam in combination with hyperbaric Bupivacaine $0.5 \%$.

\section{KEYWORDS}

Bupivacaine, Fentanyl, Midazolam, Spinal Anaesthesia.

HOW TO CITE THIS ARTICLE: Suraj HS, Vinod CN. A comparative study of intrathecal bupivacaine with fentanyl and bupivacaine with midazolam in lower abdominal and lower limb surgeries. J. Evolution Med. Dent. Sci. 2017;6(46):3565-3567, D0I: 10.14260/Jemds/2017/768

\section{BACKGROUND}

Subarachnoid blockade is the most commonly used regional anaesthetic technique for lower abdominal surgery. Spinal block is easy to perform, economical and produces rapid onset of anaesthesia. One of the main disadvantages of spinal anaesthesia is its limited duration of action and hence lack of post-op analgesia. A number of adjuvants such as clonidine, fentanyl and others have been studied to prolong the effect of spinal anaesthesia.1.2 Fentanyl is a highly lipophilic $\mu$ receptor. Opioid agonist as an adjuvant to hyperbaric bupivacaine in spinal anaesthesia provides good quality of

Financial or Other, Competing Interest: None.

Submission 05-05-2017, Peer Review 31-05-2017,

Acceptance 02-06-2017, Published 08-06-2017.

Corresponding Author:

Dr. Holalu Shankaregowda Suraj,

No. 632, $8^{\text {th }}$ Main, $3^{\text {rd }}$ Stage,

$3^{\text {rd }}$ Block, Basaveshwaranagar,

Bangalore - 79.

E-mail:dr.suraj99@gmail.com

DOI: $10.14260 /$ jemds $/ 2017 / 768$

(c) $(1)$ intraoperative and prolonged postoperative analgesia with minimal side effects. ${ }^{3,4}$ We decided to compare the clinical efficacy of intrathecal Fentanyl versus Midazolam when added to hyperbaric Bupivacaine and to evaluate the effect of each on the duration, quality of spinal block, adverse effect and complications.

\section{MATERIALS AND METHODS}

A randomised, comparative study was carried out at Kempegowda Institute of Medical Sciences and Hospital, Bangalore. After obtaining Institutional Ethical Committee approval and written informed consent, patients belonging to ASA class I and II, aged 18 - 60 years scheduled for lower limb and lower abdominal surgeries under spinal anaesthesia were enrolled in the study. Patients with h/o uncontrolled hypertension, allergy to the study drug, heart block/dysrhythmias, contraindication for spinal anaesthesia and failure of spinal block were excluded from the study. Based on the results of the study by Naina et $\mathrm{al}^{3}$ and taking $\alpha$ error of .025 and $\beta$ error of .05 , the sample size was calculated. The sample size came to $30 \mathrm{in}$ each arm. Since the 
study duration was for a period of one year from May 2015 to April 2016, we have included all the patients who gave written consent and fulfilling the criteria during the study period. The sample size came to 100 . The study subjects were divided into 2 groups (50 subjects in each arm) based on simple randomisation without replacement. All the subjects who picked even numbers were administered drug $\mathrm{F}$ and who picked odd numbers were administered drug $\mathrm{M}$.

All patients were examined and investigated a day prior to surgery and were familiarised with visual analogue scale (VAS). ${ }^{5}$ They were advised fasting for 6 hours and received alprazolam $0.5 \mathrm{mg}$ the night before surgery.

In the operation theatre, pulse oximetry, electrocardiogram and non-invasive blood pressure were attached and baseline parameters were recorded and monitoring was initiated.

Intravenous access was secured and all patients were preloaded with ringer lactate $10 \mathrm{~mL} / \mathrm{kg}$. Under all aseptic precautions, patients in sitting position, lumbar puncture was performed at L3-L4 interspace using 26-Quincke spinal needle. Patients were randomly divided into 2 groups with 50 patients in each group.

Group M- Received $3.0 \mathrm{~mL}$ volume of $0.5 \%$ hyperbaric bupivacaine and $0.5 \mathrm{~mL}$ ( $2.5 \mathrm{mg}$ ) of Midazolam.

Group F- Received $3.0 \mathrm{~mL}$ volume of $0.5 \%$ hyperbaric bupivacaine and $0.5 \mathrm{~mL}$ ( 25 micrograms) of Fentanyl.

Patients were made supine following the block and oxygen $5 \mathrm{~L} / \mathrm{min}$ were given through a face mask. The onset and the duration of sensory block, highest level of sensory block, time to reach the highest dermatome level of sensory block, motor block onset, time to complete motor block recovery and duration of spinal anaesthesia were recorded.

The onset of sensory block was defined as the time between injection of drug and the absence of pain to pinprick to highest dermatome level. Then testing was conducted every 10 mins until the point of 2 segment regression of the block was observed. The motor level was assessed according to modified Bromage scale.

\section{Grade 0}

The patient is able to move hip, knee and ankle.

\section{Grade 1}

Patient is unable to move the hip, but is able to move the knee and ankle.

\section{Grade 2}

Patient is unable to move the hip and knee, but is able to move the ankle.

\section{Grade 3}

Patient is unable to move the hip, knee and ankle.

Vitals were recorded at $1,2,3,4,5,10,15,20,25,30 \mathrm{mins}$ and subsequently every 30 mins. Hypotension defined as a decrease of systolic blood pressure more than $30 \%$ from baseline and was treated with IV bolus of $6 \mathrm{mg}$ Ephedrine and IV fluids as required. Bradycardia defined as heart rate $<50$ bpm was treated with IV atropine $0.6 \mathrm{mg}$. The incidence of nausea and vomiting and sedation were recorded. Sedation was assessed by modified Ramsay sedation scale-

1. Patient anxious and agitated or restless.

2. Patient co-operative, oriented and tranquil.
3. Responds to verbal commands while sleeping.

4. Exhibits brisk response to light glabellar tap or loud noise while sleeping.

5. Sluggish response to light glabellar tap or loud noise while sleeping.

6. No response to light glabellar tap or loud noise while sleeping.

Post-operatively, the regression time for sensory and motor block were recorded in a post anaesthesia care unit along with the vital signs and Visual Analogue Scale (VAS) score. Any patient showing VAS more than or equal to 3 was given diclofenac intramuscularly as rescue analgesia. All durations were calculated considering the time of spinal injection as time zero. Patients were discharged from PACU after sensory regression to $\mathrm{S} 1$ dermatome and Bromage 0 .

Data obtained were tabulated and analysed using Statistical Package for Social Science (SPSS 16.0 evaluation version). Descriptive data are presented as mean and SD. The comparison was studied using the chi square test or Fisher's test as appropriate with a ' $p$ ' value reported at the 95\% confidence interval. $\mathrm{P}<0.05$ was considered statistically significant.

\section{RESULTS}

The groups were comparable with respect to age, height, weight and ASA physical status (Table 1). The characteristics of block and regression time are summarised in (Table 2).

\begin{tabular}{|c|c|c|c|}
\hline \multicolumn{2}{|c|}{ Variables } & Group M & Group F \\
\hline \multirow{2}{*}{$\begin{array}{c}\text { Age } \\
\text { (Years) }\end{array}$} & Mean & 43.37 & 41.93 \\
\cline { 2 - 4 } & SD & 5.149 & 7.643 \\
\cline { 2 - 4 } & Range & 30.56 & 28.60 \\
\hline \multirow{2}{*}{$\begin{array}{c}\text { Height } \\
(\mathrm{cm})\end{array}$} & Mean & 159.9 & 160.7 \\
\cline { 2 - 4 } & SD & 5.252 & 5.563 \\
\cline { 2 - 4 } & Range & $146-170$ & $148-170$ \\
\hline \multirow{2}{*}{$\begin{array}{c}\text { Weight } \\
\text { (kg) }\end{array}$} & Mean & 60.40 & 61.13 \\
\cline { 2 - 4 } & SD & 7.587 & 10.187 \\
\cline { 2 - 4 } & Range & 43.75 & 43.90 \\
\hline \multicolumn{3}{|c|}{ Table 1. Demography } \\
\hline
\end{tabular}

\begin{tabular}{|c|c|c|c|}
\hline Variables & \begin{tabular}{|c|} 
Group M \\
(Mean \\
+- SD) \\
\end{tabular} & \begin{tabular}{|c|} 
Group F \\
(Mean \\
+- SD) \\
\end{tabular} & $\begin{array}{c}\text { P- } \\
\text { Value }\end{array}$ \\
\hline $\begin{array}{l}\text { Onset of Sensory } \\
\text { Block in Secs. }\end{array}$ & $\begin{array}{c}165.40 \pm \\
11.61\end{array}$ & \begin{tabular}{|c|}
$144.50 \pm$ \\
14.01
\end{tabular} & $<0.001$ \\
\hline $\begin{array}{l}\text { Onset of Motor Block } \\
\text { to Bromage in Secs. }\end{array}$ & $\begin{array}{c}242.80 \pm \\
11.53\end{array}$ & \begin{tabular}{|c|}
$220.14 \pm$ \\
42.71
\end{tabular} & $<0.001$ \\
\hline $\begin{array}{l}\text { Time from Injection to } \\
\text { Highest Sensory Level }\end{array}$ & $\begin{array}{c}12.53 \pm \\
1.2 \\
\end{array}$ & \begin{tabular}{|c|}
$10.97 \pm$ \\
1.2 \\
\end{tabular} & $<0.001$ \\
\hline $\begin{array}{l}\text { Time for Two Segment } \\
\text { Regression (in mins) }\end{array}$ & $\begin{array}{c}81.50 \pm \\
5.41\end{array}$ & $\begin{array}{c}118.00 \pm \\
4.80\end{array}$ & $<0.001$ \\
\hline $\begin{array}{l}\text { Time for Sensory Regression } \\
\text { to L2 Segment (in mins) }\end{array}$ & \begin{tabular}{|c|}
$147.30 \pm$ \\
8.71
\end{tabular} & $\begin{array}{c}172.30 \pm \\
5.08 \\
\end{array}$ & $<0.001$ \\
\hline $\begin{array}{c}\text { Time (in mins) for } \\
\text { Complete Motor Recovery }\end{array}$ & $\begin{array}{c}183.20 \pm \\
5.88\end{array}$ & \begin{tabular}{|c|}
$201.20 \pm$ \\
29.63
\end{tabular} & $<0.001$ \\
\hline $\begin{array}{l}\text { Rescue Analgesia } \\
\text { (in mins) }\end{array}$ & $\begin{array}{c}226.67 \pm \\
15.20\end{array}$ & $\begin{array}{c}381.67 \pm \\
38.9\end{array}$ & $<0.001$ \\
\hline \multicolumn{4}{|c|}{ Table 2. Characteristics of Block } \\
\hline
\end{tabular}

The onset time of block, both sensory up to T10 dermatome and motor to Bromage 3 scale was rapid in the Group F (144.50 $\pm 14.01 \mathrm{~min}$ and $220.14 \pm 42.71 \mathrm{~min})$ in comparison with Group M (165.40 $\pm 11.61 \mathrm{~min}$ and $242.80 \pm$ $11.53 \mathrm{~min}$ ), P-value $<0.05$. There was no difference between 
Group F and M in the highest level of block achieved. Block regression was significantly slower with the addition of Intrathecal Fentanyl (Group F) as compared with Group M, as both time to two segment regressions and time to L2 segment regression were significantly slower with intrathecal Fentanyl, P-value $<0.05$. The regression of motor block to Bromage 0 was significantly slower in Group F (201.20 \pm $29.63 \mathrm{~min})$ compared to Group $\mathrm{M}(183.20 \pm 5.88 \mathrm{~min})$, Pvalue $<0.05$. The time to rescue analgesia was significantly longer in Group F (381.67 $\pm 38.9 \mathrm{~min})$ as compared to Group M (226.67 $\pm 15.20 \mathrm{~min})$.

There was no significant difference in the mean value of heart rate and mean arterial pressure in the first hour after performing the spinal anaesthesia and the first hour in the PACU between the two groups. The sedation score was more in Group $\mathrm{M}$ patients $(3.4 \pm 0.3)$, which was statistically significant. The $\mathrm{SPO}_{2}$ was higher than $95 \%$ in all patients either in the intraoperative or in the PACU time. 24 hours and 2 weeks followup did not show neurological impairment related to spinal anaesthesia such as back, buttock or leg pain, headache or any neurological deficit.

\section{DISCUSSION}

Different agents such as magnesium sulphate, phenylephrine, clonidine has been used as adjuvant for prolonging the duration of spinal anaesthesia. Administration of fentanyl intrathecally is an established method for intraoperative anaesthesia and to supplement postoperative anagesia. ${ }^{6}$ The spread of fentanyl after administration into cerebrospinal fluid include movement from the cerebrospinal fluid into the opioid receptors or other non-specific binding sites in the spinal $\operatorname{cord}^{7}$ and rostral migration via the cerebrospinal fluid to supraspinal sites. Because of the high affinity of fentanyl with nonspecific binding sites on the lipid surface, only a small proportion of the administered dose migrates to the cervical region.

BN Biswas et al studied that $12.5 \mu \mathrm{g}$ of fentanyl added to 2 $\mathrm{mL}$ of $0.5 \%$ bupivacaine for subarachnoid block would markedly improve intraoperative anaesthesia, ${ }^{8}$ and reduced the demand for postoperative analgesic. We had the same results in our study.

Nocioception action of Midazolam ${ }^{9}$ is well documented. RLM Faull et al showed that spinally mediated analgesia and the segmental analgesia produced by intrathecal midazolam is mediated by the benzodiazepine-GABA receptor complex. They demonstrated that benzodiazepine-GABA receptor were distributed consistently in similar fashion in the grey matter of cervical, thoracic and sacral regions of the spinal cord.

Goodchild and Noble in 1987 observed that $0.3-2 \mathrm{mg}$ of intrathecal midazolam ${ }^{10}$ interrupts somatic nociceptive afferent pathway of pain. However, it did not significantly block the abdominal visceral nociceptive afferent pathway of pain.

Waldvogel et al investigated the regional, cellular and subcellular distribution of GABA, GABA receptors ${ }^{11}$ and benzodiazepine receptors. The results showed a close correspondence in the regional distributions of GABA, GABA (GABA-A and GABA-B) receptors and benzodiazepine receptors. The most significant side effect reported about the use of intrathecal Fentanyl is pruritus, but in our study it was not significant.
Better quality of Anaesthesia was noted with the intrathecal Fentanyl group as compared with Intrathecal Midazolam group as Opioid receptors were abundant than GABA receptors in spinal cord.

\section{CONCLUSION}

Intrathecal Fentanyl supplementation of spinal block produces earlier onset and prolonged duration of sensory and motor block without associated significant haemodynamic alterations as compared with Midazolam as adjuvant to spinal bupivacaine in lower limb and lower abdominal surgeries.

\section{REFERENCES}

[1] Elia N, Culebras X, Mazza C, et al. Clonidine as an adjuvant to intrathecal local anaesthetics for surgery: systematic review of randomized trials. Reg Anaesth pain Med 2008;33(2):159-67.

[2] Hunt CO, Naulty JS, Bader AM, et al. perioperative analgesia with subarachnoid fentanyl-bupivacaine for caesarean delivery. Anaesthesiology 1989;71(4):53540.

[3] Dalvi NP, Patil N. Comparison of effect of intrathecal fentanyl bupivacaine and tramadol-bupivacaine combination on postoperative analgesia in lower abdominal surgeries. Research and Innovation in Anesthesia 2016;1(2):35-40.

[4] Bajwa BS, Singh AP, Rekhi AK. Comparison of intrathecal clonidine and fentanyl in hyperbaric bupivacaine for spinal anesthesia and postoperative analgesia in patients undergoing lower abdominal surgeries. Saudi J Anaesth 2017;11(1):37-40.

[5] Katz J, Melzack R. Measurement of pain. Surg Clin North Am 1999;79(2):231-52.

[6] McQuay HJ, Sullivan AF, Smallman K, et al. Intrathecal opioids, potency and lipophilicity. Pain 1989;36(1):111-5.

[7] Gourlay GK, Murphy TM, Plummer JL, et al. Pharmacokinetics of fentanyl in lumbar and cervical CSF following lumbar epidural and intravenous administration. Pain 1989;38(3):253-9.

[8] Biswas BN, Rudra A, Bose BK, et al. Intrathecal fentanyl with hyperbaric bupivacaine improves analgesia during caesarean delivery and in early postoperative period. Indian J Anaesth 2002;46(6):469-72.

[9] Kim MH, Lee YM. Intrathecal midazolam increases the analgesic effects of spinal blockade with bupivacaine in patients undergoing haemorrhoidectomy. J Anaesth 2001;86(1):77-9.

[10] Faull RL, Villiger JW. Benzodiazepine receptors in the human spinal cord: a detailed anatomical and pharmacological study. Neuroscience 1986;17(3):791-802.

[11] Waldvogel HJ, Faull RL, Jansen KL, et al. GABA, GABA receptors and benzodiazepine receptors in the human spinal cord: an autoradiographic and immunehistochemical study at the light and electron microscopic levels. Neuroscience 1990;39(2):361-85. 